\title{
$\equiv$ MANAGEMENT
}

УДК 50.03.05

DOI: $10.24045 /$ et.2017.3.5

\section{ВЗАИМОДЕЙСТВИЕ УЧАСТНИКОВ ПРОБЛЕМНОЙ СИТУАЦИИ}

\author{
Т. В. Моисеева \\ Ю. В. Мятишкин
}

Кандидат экономических наук, дочент

ученый секретарь

инженер

Институт проблем управления

сложными системами

Российской академии наук

2. Самара, Россия

\section{THE INTERACTION OF PARTICIPANTS INVOLVED IN THE PROBLEM SITUATION}

T. V. Moiseeva

Yu. V. Myatishkin
Candidate of Economical Sciences

assistant professor, science secretary

engineer

Institute for the Control of Complex Systems

of Russian Academy of Sciences

Samara, Russia

\begin{abstract}
The theory of intersubjective management is focused on finding a way out of the problem situation in which actors find themselves. Being motivated, actors are ready to invest their own resources (financial, material, time) to solve the problem. However, very often it can't be possible to make the decision without supporting assistance by the other people involved in the problem, but not motivated as much as the actors. To organize such interaction in large communities is especially difficult. The specificity of intersubjective management (opposite to traditional management) creates the problem faced by actors who find themselves in problem situations connected with interaction of actors and non-actors, which is only beginning to be explored. Therefore, the aim of this article is to raise the problem of actors interaction with other participants in a problem situation.
\end{abstract}

Keywords: intersubjective management, problem situation, heterogenous actors, non- actors, interaction, consensus, passivity.

\section{Введение}

Теория управления [1] ориентирована на поиск выхода из проблемной ситуации, в которой оказались акторы, путем переговоров с применением технологии консенсуса. Будучи мо- тивированными на получение результата, акторы готовы вкладывать собственные ресурсы (финансовые, материальные, временные) для разрешения ситуации.

Однако очень часто принять решение оказывается невозможно, не 
получив согласия и не убедив других участников, вовлеченных в проблему, но не мотивированных также сильно, как акторы. Это связано с тем, что ресурсов нескольких акторов становится недостаточно, и они ищут их дополнительные источники во внешней среде, либо «в одной упряжке» (т. е. не могут двигаться в разных направлениях одновременно) оказываются не только акторы. Причем один и тот же человек может оказаться активным актором в одной ситуации и пассивным участником - в другой. Особенно сложно оказывается организовать такое взаимодействие в достаточно больших сообществах, например, при принятии решения внутри студенческой группы или коллектива предприятия, в многоквартирном доме.

Технология принятия решения акторами рассмотрена в $[1 ; 3]$. Однако, специфика интерсубъективного управления, нетрадиционного для современного менеджмента, принятого в большинстве организаций, порождает проблему, с которой сталкиваются акторы, оказавшиеся в проблемной ситуации, связанную с взаимодействием акторов и неакторов, которая пока только начинает исследоваться. Сегодня организация их взаимодействия не регламентирована, не существует правил и технологий, следуя которым они могли бы прийти к консенсусу, что затрудняет применение интерсубъективного управления в больших группах людей. Поэтому целью данной статьи является поднять проблему взаимодействия акторов с прочими участниками про- блемной ситуации и наметить пути выхода из нее.

\section{1. Роль гетерогенных} акторов в процессах принятия решения при интерсубъективном управлении

Ключевая фигура теории интерсубъективного управления [1] гетерогенный актор, который не является объектом управления, что характерно для традиционного менеджмента, его деятельность базируется не на принуждении, а на достижении взаимопонимания и консенсуса с другими акторами, которые не только познают мир, но и творят его. Актор мотивирован к разрешению проблемной ситуации, причем поиск выхода из нее актор ведет совместно с другими акторами. Анализ проблемной ситуации приводит актора к принятию потребностей, желаний, ценностей и целей оппонентов, наравне с осознанием собственного интересов участия в принятие решения. Интерсубъективное сознание рациональных акторов учитывает альтернативные точки зрения других индивидуумов, поскольку решение должно быть выработано совместно всеми заинтересованными лицами. Озабоченные акторы ориентированы на достижение общих целей, поэтому с готовностью рассматривают, обсуждают и затем одобряют альтернативные точки зрения в ходе дискурса, идут на компромисс и сотрудничество, стремятся выстроить конструктивные отношения партнерства, стараются овладеть коммуникативными знаниями и умениями, характеризуются наличием толе- 
рантности по отношению друг к другу и прочим лицам, участвующим в реализации принятого решения. В результате образуется общее смысловое пространство, формируется интерсубъективная модель смысла проблемной ситуации. В тех случаях, когда решение не может быть принято или реализовано без привлечения других членов сообщества, не погруженных в проблемную ситуацию как акторы, необходимо выстраивать отношения с неакторами и привлекать их в качестве союзников и партнеров к процессу урегулирования проблемной ситуации, что представляется важным элементом теории и практики интерсубъективного управления. В такой ситуации оказываются, например, жители многоквартирного дома, живущие на последнем этаже. Они погружены в проблему, связанную с крышей, протекающей над их квартирой. Ее ремонт возможен только в том случае, если все прочие жильцы дома (не погруженные в данную проблему) поддержат решение о том, что в первую очередь необходимо отремонтировать именно крышу. Оказавшиеся в данной проблемной ситуации акторы вынуждены будут договариваться с соседями и вырабатывать общее решение.

\section{2. Причины инертности} поведения не-акторов в процессах принятия решения

Если акторы являются заинтересованными лицами, мотивированными к поиску выхода из проблемной ситуации, то прочие действующие лица могут оказаться не только пассивными участниками событий, но и активными противниками обсуждения и внедрения предлагаемых решений. Это может быть связано со многими факторами, определяемыми как психо-физическими характеристиками самого человека, так и влиянием на него внешней среды.

1. Если акторы осознают проблемную ситуацию, оказываясь погруженными в нее, то в отличие от них не-акторы эту ситуацию познают, находясь вне ее. Внутренняя мотивация отсутствует, поэтому они неохотно подключаются к процессу урегулирования ситуации. Необходимы усилия по их убеждению для достижения сходимости в принятии решения.

2. Для эффективного взаимодействия люди должны владеть коммуникативными навыками, хотеть и уметь прийти к согласию. Однако, многие из нас не умеют договариваться и признавать чужое мнение. Не будучи внутренне мотивированы на разрешение ситуации, не-акторы не торопятся преодолеть собственную инертность и подключится к более активным акторам.

3. Практически любая инициатива акторов сталкивается с сопротивлением изменениям, вызываемым страхом перед воображаемыми или реальными негативными последствиями изменений. Заставить не-акторов не сопротивляться невозможно, однако за первичным отторжением и сопротивлением следует анализ возможных последствий, на котором людям необходима информационная подпитка для формирования положительного от- 
ношения к нововведениям. Получив информацию, не-актор может подключиться к обсуждению ситуации, увидев в этом определенные выгоды и для себя, либо поняв, что при бездействии он что-то теряет.

4. Складывающаяся в современном обществе гражданская культура социума тяготеет к подданническому типу. Подданнические отношения означают безусловное превосходство обязанностей перед правами и слепое повиновение государству, когда человек чувствует себя его подопечным, будучи уверенным в том, что невозможно прожить без постоянной заботы со стороны власти. Подавляющее большинство неакторов с этим обстоятельством свыклось и, в основном, не стремится что-то исправить, противостоит предложениям заняться самим решением своих же проблем и не видит других возможностей своего существования. Они убеждены, что попытка повлиять на ситуацию обречена на неудачу, что, несомненно, делает не активных членов различных сообществ инертными в ожидании того, что кто-то примет решение за них.

5. Изменение нравственных и моральных норм социума, вызванное стремлением культуры от коллективистского типа к индивидуалистическому усложняет встраивание не-актора в процессы интерсубъективного управления для совместного поиска решения в проблемной ситуации. Этому способствует снижение потенциала солидарности и ослабление ориентации человека на интересы группы, сотрудничество и взаимопомощь.
Атомизация социума сегодня проявляется «в виде неспособности людей коллективно отстаивать свои нужды и интересы» [2]. Рыночная экономика, определяющая отношения собственности, направленные против коллективных ценностей, а также индивидуализация потребительского общества способствуют обособлению индивида от тех групп, в которых акторы пытаются найти выход из проблемной ситуации.

6. Еще одна причина инертности поведения людей в проблемной ситуации - высокая «себестоимость» принятия совместного решения путем консенсуса. К сожалению, многие из нас привыкли полагаться на авторитарно принятое решение или рассчитывает, что голосование большинством голосов приведет к оптимальному решению и сэкономит время, в то время как поиск смысла проблемной ситуации путем консенсуса потребует больших временных затрат.

7. Стремление уклониться от принятия общего решения может быть вызвано и тем, что участие в принятии решения подразумевает и впоследствии ответственность за него, которую не-актор не желает на себя принимать.

\section{3. Что делать?}

Проблема вовлечения разных членов сообществ в принятие совместных решений может стоять достаточно остро, если без этого решение не может быть принято.

Для того чтобы преодолеть инертность не-акторов, необходимо воспитание и обучение людей совместному принятию решений, кото- 
poe может проводиться не только в школах и вузах, но и в рамках самих сообществ, ориентированных на формирование социальных навыков их членов, чьи экономические возможности ограничивают спектр принимаемых решений. Чем выше уровень содействия акторов и неакторов друг другу в ходе обсуждения общих задач, тем более дорогостоящие решения способна принять вся группа. При наличии низкого уровня социальных навыков в групповом принятии ответственных решений обучение следует начинать, выбирая такие темы для обсуждения, реализация которых изначально одобряется большинством членов сообщества.

Решение задачи достижения консенсуса акторов с остальными членами сообществ несет в себе существенные изменения социальных взаимоотношений, повышает качество жизни за счет улучшения отношений между людьми, вызывая рост инвестиционной привлекательности экономики сообществ.

\section{Библиографический список}

1. Vittikh V. A. Introduction to the theory of intersubjective management // Group Decision and Negotiation. - 2015. Issue 1. - Vol. 24. - P. 67-95.

2. Дамье В. Атомизация общества и социальная самоорганизация: российский контекст. URL: http://litrus.net/book/read/108270 (дата обращения: 17.08.17)

3. Моисеева Т. В. Интерсубъективное управление: от теории к практике // Проблемы управления и моделирования в сложных системах: труды XVIII Междунар. конф. - Самара : Изд-во ООО «Офорт», 2016. - 464 с. - С. 53-62.

\section{Bibliograficheskij spisok}

1. Vittikh V. A. Introduction to the theory of intersubjective management // Group Decision and Negotiation. - 2015. - Issue 1. - Vol. 24. - P. 67-95.

2. Dam'e V. Atomizacija obshhestva i social'naja samoorganizacija: rossijskij kontekst. URL: http://litrus.net/book/read/108270 (data obrashhenija: 17.08.17)

3. Moiseeva T. V. Intersub'ektivnoe upravlenie: ot teorii k praktike // Problemy upravlenija i modelirovanija $\mathrm{v}$ slozhnyh sistemah: trudy XVIII Mezhdunar. konf. - Samara : Izd-vo OOO «Ofort», 2016. - 464 s. - S. 53-62.

(C) Mоисеева T. B., Мятишкин Ю. В., 2017. 